\title{
Modelling Of Rock Joints Interface Under Cyclic Loading
}

https://doi.org/10.2478/sgem-2019-0030

received March 1, 2019; accepted September 2, 2019.

\begin{abstract}
The problem of numerical simulation of the material interface response under monotonic and cyclic loading is of fundamental scientific and engineering importance. In fact, such interfaces occur in most engineering and geotechnical structures. The present work is devoted to the deformational response analysis of contact interfaces under monotonic and cyclic loads. The class of materials includes rock and structural joints, soil structure interfaces, masonry and cementitious joints, localized shear bands and so on.

The aim of the proposed model is to simulate the cyclic shear test under constant normal load. The associated dilatancy effect is associated with the configurational effects of asperity interaction or dilatancy of wear debris layer. The large primary asperities are assumed as responsible for interfacial dilation and small size asperities as governing frictional sliding and hysteresis response. The elliptic loading yield function is assumed to translate and rotate during progressive or reverse loading events. The model formulation is discussed and confronted with experimental data.
\end{abstract}

Keywords: cyclic shear test; asperity degradation; elliptic yield surface; material interface response; rock joint interface

\section{Introduction}

The most important effects related to monotonic and cyclic response of contact interfaces of brittle materials are analyzed in this paper. The class of the materials is quite wide and includes rock joints, artificial and natural

\footnotetext{
*Corresponding author: Jan Maciejewski, Warsaw University Of Technology, Faculty Of Automotive And Construction Machinery Engineering, Institute Of Construction Machinery, E-mail: ???? Sebastian Bąk, Pawet Ciężkowski, Warsaw University of Technology, Faculty of Automotive and Construction Machinery Engineering, Institute of Construction Machinery
}

joints, existing cracks in rocks, brittle materials, masonry and other cementitious joints. Rock masses contain discontinuities, such as faults, joints, cracks and other plane of weakness.

The mechanical behavior of rock masses depends not only on the properties of intact structure but also on the properties of the interfaces. The mechanical behavior of such contact interfaces (shear strength), shear and normal deformation dominates the mechanical behavior of in situ rock masses under different loading condition.

Frictional properties of joints are usually investigated by performing shear test under constant normal load $\mathrm{CNL}^{[11]}$ (Fig.1) and constant normal stiffness CNS condition.

Two types of interfaces can be considered: first as a natural joint, where the surface morphology is described by the joint roughness coefficient JRC ${ }^{[6,35]}$ (Fig. 2a), and second, where the interface is artificial sawcut material joint and the surface morphology is represented by periodic piecewise linear or curvilinear shape ${ }^{[11,34]}$ (Fig. $2 \mathrm{~b}, \mathrm{c})$. The contact interface issue was under investigation both in laboratory tests [10], [16], [19] and from the modeling point of view [2], [7], [12], [17], [29]. Most of the researchers focus on monotonic loads [11], [25], [26], but cyclic loads, where degradation of the contact surface occur [9], [27] can also be found.

In several studies, the surface roughness is considered as a composition of asperities of two different length scale: primary asperities (largest one) and secondary (or subordinated) asperities (Fig. 3). On each contact surface, there are some kind of surface asperities, which can be seen in Fig. 2. Each rock produces distinctive structure during cracking. The resulting asperities correlate with the length of the crack. In the literature, there are many works dealing with the influence of the shape of these asperities on the behavior of the cyclic shear process. ${ }^{[1,26]}$ For the analyzed issues, the most important influence on tangential stresses tendencies and changes in the contact layer height have primary asperities. . $^{[4,18]}$

The basic model used in the analysis of soil deformation processes (digging, compaction) is a model of perfectly plastic material that meets the Coulomb or Drucker-Prager condition of plasticity and associated or 


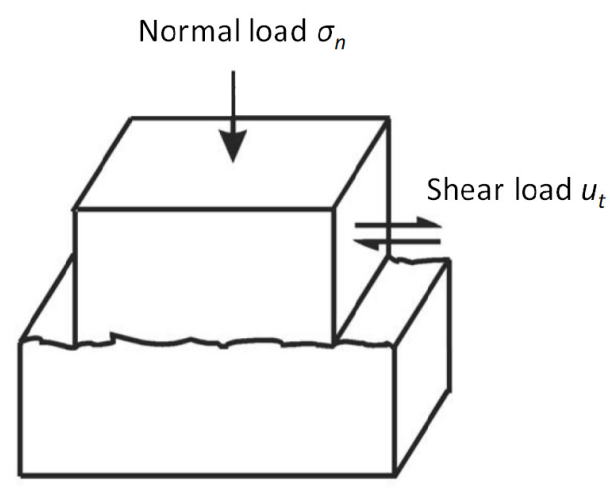

Figure 1: Shear test of rock joint interface ${ }^{[12]}$

a)

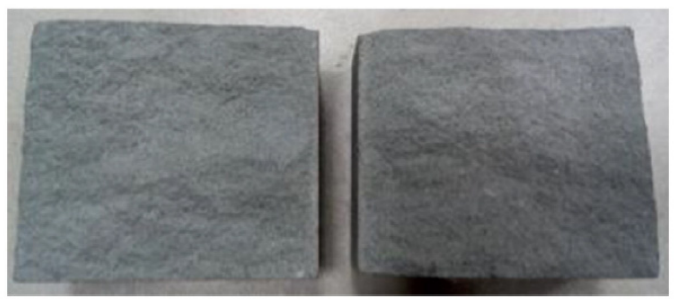

b)

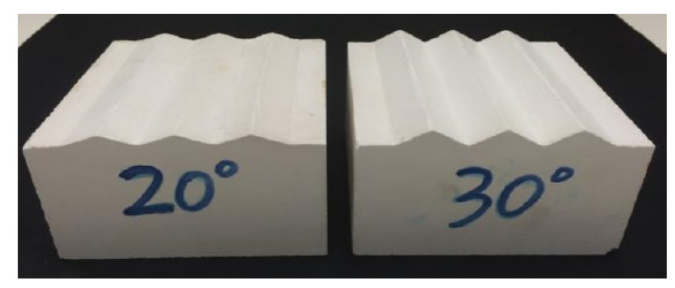

c)

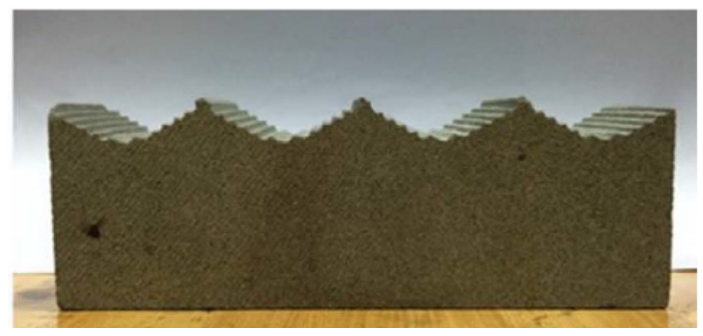

Figure 2: Types of rock joints: a) natural joint, ${ }^{[15]} \mathrm{b}, \mathrm{c}$ ) artificial rock interfaces ${ }^{[13,16]}$

non-associated flow rules. In this model, the hardening or softening of the material is omitted and unlimited deformability in the state of plastic flow is assumed. Coulomb's linear condition gives a good estimate for dense materials. However, for loose and susceptible materials, when there is simultaneous compaction and loosening during deformation processes, nonlinear models have found widespread use. In this type of processes, models

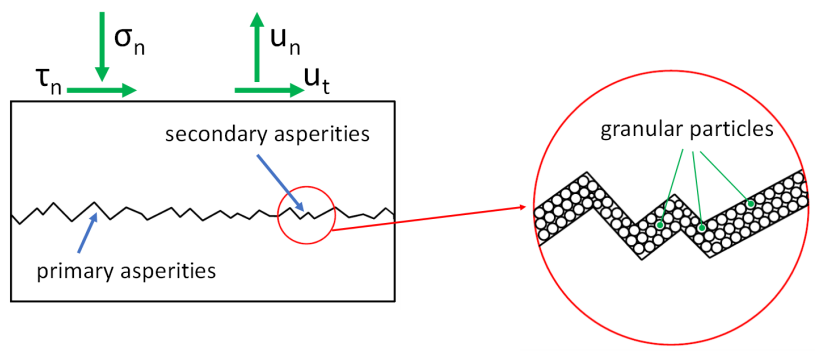

Figure 3: Primary and secondary asperities

with a closed yield surface are used (i.e., ellipse). Surfaces with a closed yield criterion, which can describe the effects of compaction and loosening, and deformation of the soil for complex load paths, have been used by many researchers, that is, [3], [5], [24], [25], [27], [28] and [30]. To describe the state of deformation, both associated and non-associated flow rules were used, as well as various concepts of density and deviatoric hardening. To describe the yield surface, elliptical surfaces, super ellipse or irregularly shaped surfaces were used.

In the presented simulation, the elliptical model defined in the space of contact stresses $\left(\sigma_{n}, \tau_{n}\right)$ was used to describe the material in contact layers. Models with elliptical yield surface were successfully used to describe the behavior of the shear band deformation, which is formed in the rocks [9], [20] and [21]. The evolution of the state of stress and strain in connection with the effects of wear and damage is presented in the paper [19].

Typical dilation and stress response in cyclic shear test is shown in Fig. 4. The shearing displacement is usually accompanied by the dilation of the joint. The character of dilation response depends on the joint type (primary asperity shape). With the change of the sliding direction, the dilation decreases until the shear displacement changes its sign and then increases again. For repeated cyclic shearing at very low pressures, the dilation response is reversible (Fig. 4a), while under high normal pressure, the dilation decreases with increasing number of cycles (Fig. 4b). This effect is related to wear and crushing of asperities and granular fraction formation on the contact surfaces.

The granular layer consists of free particles with different shapes and sizes. In cyclic shear test, the effect of compaction associated with the shear direction changing is observed (Fig. 4c). To describe such a behavior, the phenomenological 2D model of a granular layer is proposed (3D is not considered). This model is based on elliptic yield surface with density and deviatoric hardening described by the rotation of yield surface. 
a)
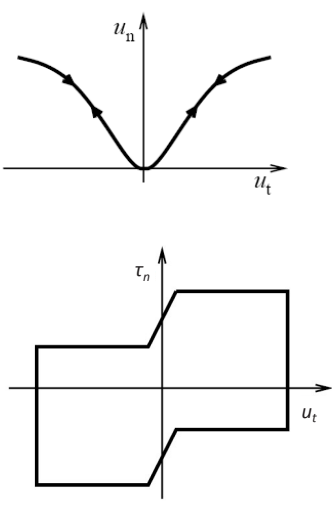

b)

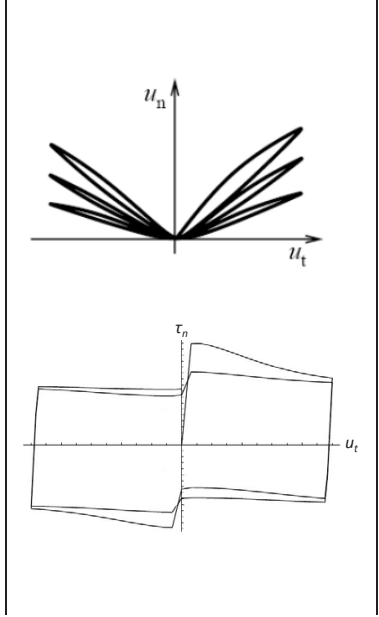

c)
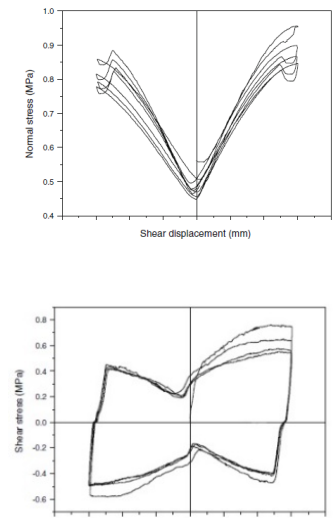

Figure 4: Dilation and stress in cyclic shear test: a) cyclic reversible dilatancy, b) cyclic dilatancy degradation, c) experimental data ${ }^{[22]}$

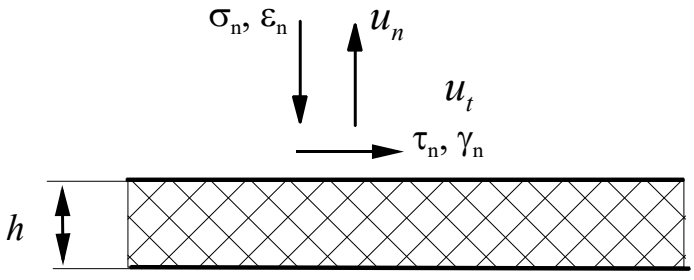

Figure 5: Scheme of the load of joint interface

In this work it is assumed that the primary asperities are responsible for interfacial dilation, while the secondary asperities govern the frictional conditions at the inclined contact of primary asperities (Fig. 3).

\section{Deformation on the critical plane}

The rock joint interface is treated as the contact zone with properties different than the rock block with shape described by asperities. During shearing, this zone adopts the properties of granular material. The granular layer with thickness $h$ is sheared as the result of tangential displacement $u_{t}$ with an amplitude $u 0$ under normal stress load $\sigma_{n}$ (Fig. 5).

Material under cyclic shear test is in a certain state of stress and strain in accordance with (1).

$$
\sigma=\left[\begin{array}{l}
\sigma_{n} \\
\tau_{n}
\end{array}\right], \varepsilon=\left[\begin{array}{l}
\varepsilon_{n} \\
\gamma_{n}
\end{array}\right]
$$

where strain rate is equal to $\dot{\varepsilon}_{n}=-\frac{\dot{u}_{n}}{h}, \dot{\gamma}_{n}=\frac{\dot{u}_{t}}{h}$.
In the presented work, $\sigma_{n}, \varepsilon_{n}$ are treated as positive and displacement $u_{n}$ - as negative; so, increase in layer height has a positive value.

To describe the strain of a layer, it was assumed that the strain rates components are decomposed as elastic and plastic:

$$
\dot{\varepsilon}=\dot{\varepsilon}^{e}+\dot{\varepsilon}^{p}
$$

or

$$
\left[\begin{array}{l}
\dot{\varepsilon}_{n} \\
\dot{\gamma}_{n}
\end{array}\right]=\left[\begin{array}{c}
\dot{\varepsilon}_{n}^{e} \\
\dot{\gamma}_{n}^{e}
\end{array}\right]+\left[\begin{array}{l}
\dot{\varepsilon}_{n}^{p} \\
\dot{\gamma}_{n}^{p}
\end{array}\right]
$$

where $\dot{\varepsilon}^{p}$ and $\dot{\varepsilon}^{e}$ are elastic and plastic strain rate component, $\dot{\varepsilon}_{n}^{e}, \dot{\gamma}_{n}^{e}$ are normal and shear elastic strain rate components and $\dot{\varepsilon}_{n}^{p}, \dot{\gamma}_{n}^{p}$ are plastic components.

Also, it is assumed that constitutive relations for elastic deformation can be expressed in incremental form:

$$
\left[\begin{array}{c}
\dot{\varepsilon}_{n}^{e} \\
\dot{\gamma}_{n}^{e}
\end{array}\right]=C^{e}\left[\begin{array}{c}
\dot{\sigma}_{n} \\
\dot{\tau}_{n}
\end{array}\right]=\left[\begin{array}{cc}
1 / K_{d} & 0 \\
0 & 1 / G_{d}
\end{array}\right]\left[\begin{array}{c}
\dot{\sigma}_{n} \\
\dot{\tau}_{n}
\end{array}\right]
$$

where $K_{d}, G_{d}$ are the normal and shear moduli.

Plastic strain rate is described by the associated flow rule

$$
\dot{\boldsymbol{\varepsilon}}^{p}=\dot{\lambda} \frac{\partial F}{\partial \sigma}, \quad \dot{\lambda} \geq 0, \quad F \leq 0, \quad \dot{\lambda} F=0
$$

where $F$ is given by (6). 
a)

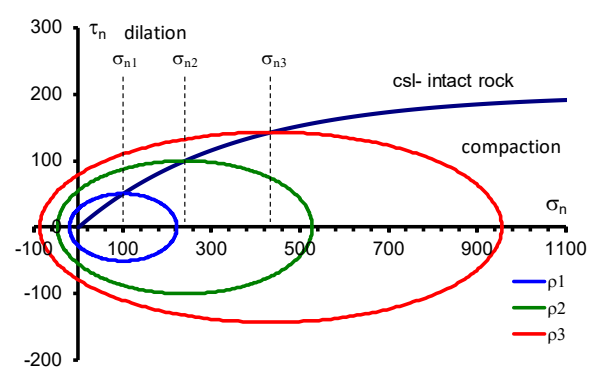

b)

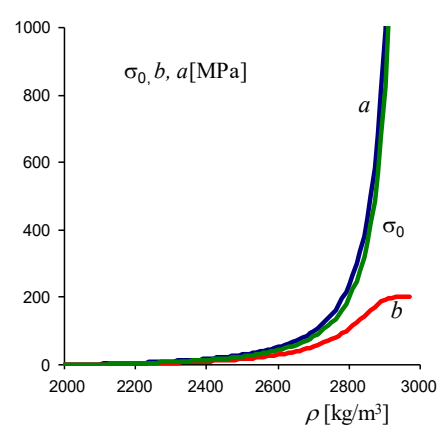

Figure 6: a) Elliptical failure surfaces and critical state line (csl) on plane $\sigma_{n}, \tau_{n}$, b) change of ellipse center $\sigma_{o}$ and semi-major and semiminor axes size $(a, b)$ as the function of density $\rho$

\section{Failure condition}

In this study, an elliptical yield function was assumed, which in the space of contact stresses $\sigma_{n}, \tau_{n}$, can be formulated as:

$$
F\left(\sigma_{n}, \tau_{n}\right)=\frac{\left(\sigma_{n}-\sigma_{0}\right)^{2}}{a^{2}}+\frac{\left(\tau_{n}\right)^{2}}{b^{2}}-1=0
$$

where $a, b$ are the sizes of semi-major and semi-minor axes of an ellipse, and $\sigma_{0}$ is the position of the center of an ellipse on the axis of normal stresses.

It was also assumed that the size of the ellipse is related to the location of its center $\sigma_{0}$ in accordance to:

$$
a=k \sigma_{0}
$$

where $k$ is a material constant.

Along with changes in the density of the material, the size and position of the yield surface changes according to the following formula:

$$
\sigma_{0}=C_{1}\left[\left(\frac{\rho_{\max }-\rho_{\min }}{\rho_{\max }-\rho}\right)^{C_{2}}-1\right]
$$

where $C_{1}, C_{2}$ are material constants and $\rho_{\max }, \rho_{\min }$ mean the highest and lowest density of the material.

It was assumed that the critical state line for which plastic flow occurs without volume changes is given by:

$$
\tau_{0}=A_{1}\left[1-e^{-A_{2} \sigma_{0}}\right]=b
$$

where $A_{1}, A_{2}$ are material constants and $\sigma_{0}$ is the stress determining the state of compaction.

The relation given above also defines the size of the semi-minor axis.

Examples of elliptical yield surfaces and the critical state line (csl) are shown in Fig. 6a. The figure shows three yield surfaces corresponding to material with densities $\rho 1<\rho 2<\rho 3$. The critical state line separates stress states for which the material is softened by loosening (positive dilation angles) and hardened by compaction (negative dilation angles).

Fig. $6 \mathrm{~b}$ shows the changes in the position of the center of ellipse $\sigma_{o}$ and the size of the semi-major and semi-minor axes $(a, b)$ as the function of density $\rho$.

Figures 7, 10, 12, 15 present simulation results for each stage of model building. All cyclic shear tests of the contact layer were performed with an amplitude of $u_{0}=$ $\pm 5 \mathrm{~mm}$ and normal load $\sigma_{n}=2,10$ and $20 \mathrm{MPa}$. Assumed material parameters are: Young modulus $E=23.13 \mathrm{GPa}$, Poisson's ratio $v=0.23$, initial density $\rho_{i n i}=2.3^{*} 10^{3} \mathrm{~kg} / \mathrm{m}^{3}$, $A_{1}=200 \mathrm{MPa}, A_{2}=2.887^{*} 10^{-2} \mathrm{MPa}^{-1}, \rho_{\max }=3^{*} 10^{3} \mathrm{~kg} / \mathrm{m}^{3}, \rho_{\min }=2$ ${ }^{\circ} 10^{3} \mathrm{~kg} / \mathrm{m}^{3}, \mathrm{C}_{1}=10 \mathrm{MPa}, \mathrm{C}_{2}=2$.

Fig. 7 a shows the changes in tangential stress value as a function of tangential displacement. For low values of normal stress $\left(\sigma_{1}\right)$ in the initial load cycle, there is a sudden increase in tangential stress and then decrease and stabilization at a much lower level limited by formula (9). As the normal load increases, this effect does not disappear. At high contact pressures (for $\sigma_{3}$ ), the tangential stress gradually increases rather than decreases. Fig. 7b shows changes in the material dilation layer thickness. For low stresses $\left(\sigma_{1}\right)$, the material loosens, while for high pressures $\left(\sigma_{3}\right)$ the compaction of the material starts immediately. 


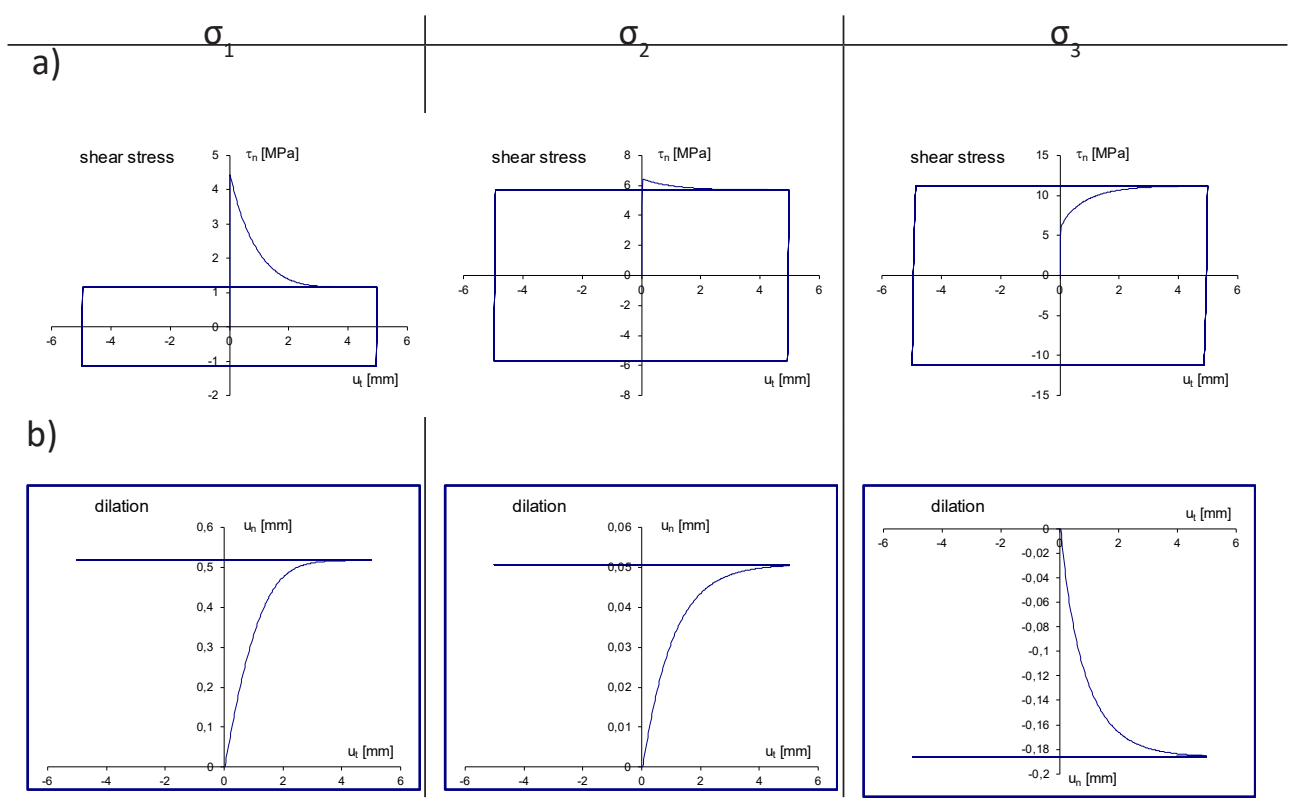

Figure 7: Simulation results for different normal loads $\left(\sigma_{1}<\sigma_{2}<\sigma_{3}\right)$ depending on the tangential displacement $u_{t}$ : a) variations of shear stress, b) variations of dilatancy

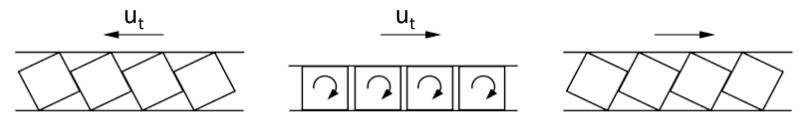

Figure 8: Configurational rearrangement of particles after the change of sliding direction

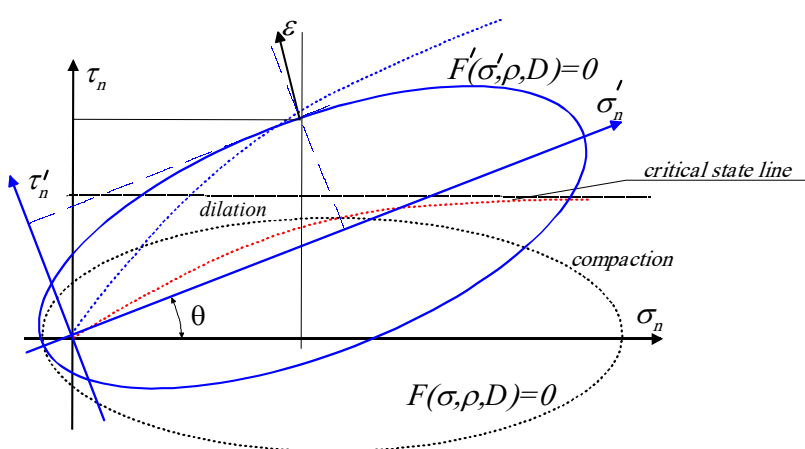

Figure 9: Change of the failure surface position by rotation through an angle $\theta$

This simple elliptical model is not able to describe the complex nature of rock joint interface, in particular, when changing the load direction. The response stabilizes just after the first load cycle.

During the change of the tangential movement direction, the grain configuration changes at the contact layer. This effect is shown in Fig. 8.
The concept of the description of the configurational rearrangement was presented in the work [31] assuming the description of the contact layer by the Coulomb condition, the non-associated flow rule and rotation of yield surface according to sliding direction. In this model, the idea of changing the position of the yield surface is shown in Fig. 9.

The rearrangement of particles is unequivocal with the change in the location of the yield surface.

The change of the failure surface position is related to the introduction of the rotation angle $\theta$ (Fig. 9). With the increase of the $u_{t}$ displacement, the surface position is changed by the angle $\theta$ to the maximum value $\pm \theta_{\max }$ depending on the deformation direction $u t$ described by the parameter $s$ (11). Rate of $\theta$ is described by (10).

$$
\begin{gathered}
\dot{\theta}=\dot{\eta} k_{t}\left(s \theta_{\max }-\theta\right) \\
s=\frac{\dot{\gamma}_{n}^{p}}{\left|\dot{\gamma}_{n}^{p}\right|}= \pm 1 \\
\dot{\eta}=\left|\dot{\gamma}_{n}^{p}\right|
\end{gathered}
$$

Where $k_{t}[-]$ is rotation parameter and $\dot{\gamma}_{n}$ is shear strain rate.

In the local coordinate system, the state of stress and strain is described by (13). 


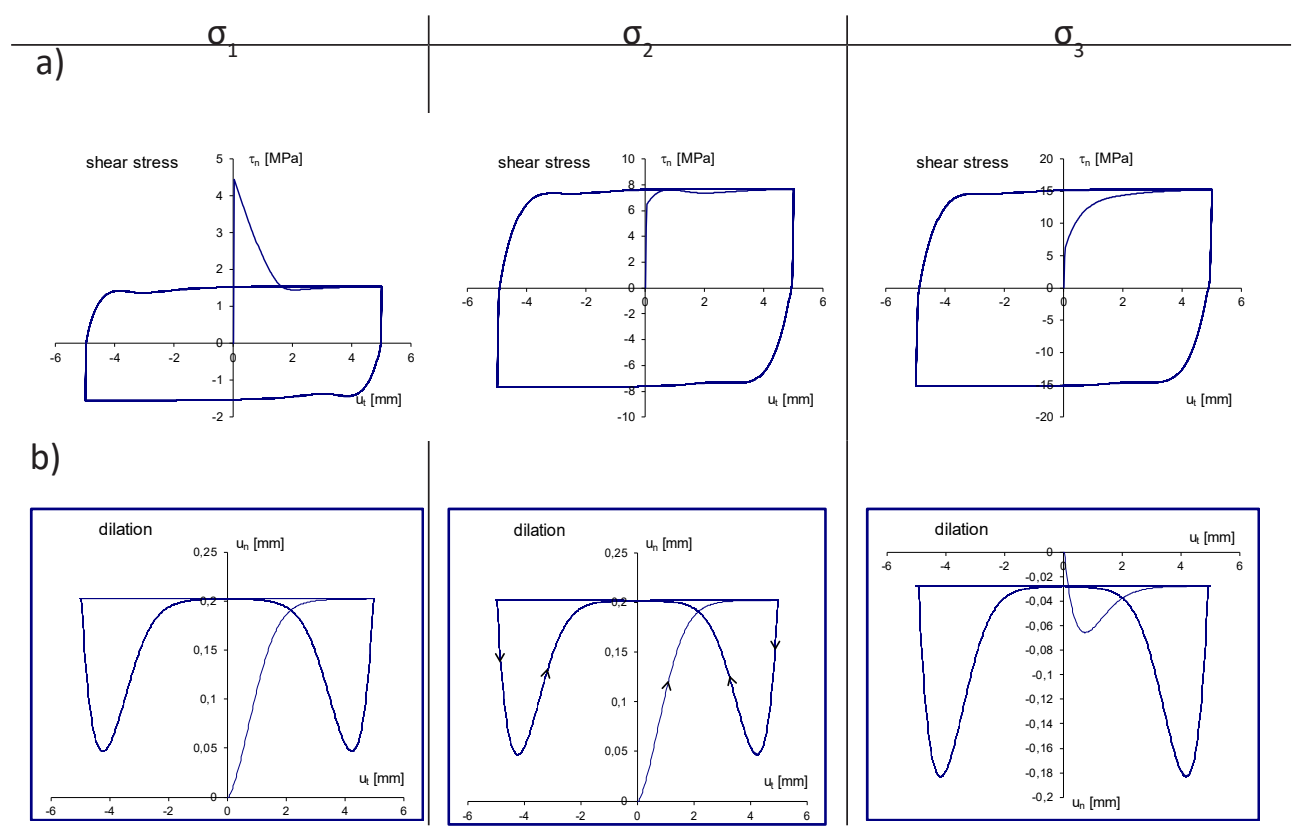

Figure 10: Simulation results for different normal loads $\left(\sigma_{1}<\sigma_{2}<\sigma_{3}, \rho_{i n i}=2.3^{*} 10^{3} \mathrm{~kg} / \mathrm{m}^{3}, \theta_{\max }=25^{\circ}\right)$ depending on the tangential displacement $u_{t}:$ a) variations of shear stress, b) variations of dilatancy

$$
\boldsymbol{\sigma}^{\prime}=\left[\begin{array}{c}
\sigma_{n}^{\prime} \\
\tau_{n}^{\prime}
\end{array}\right], \quad \dot{\boldsymbol{\varepsilon}}^{\prime}=\left[\begin{array}{c}
\dot{\varepsilon}_{n}^{\prime} \\
\dot{\gamma}_{n}^{\prime}
\end{array}\right]
$$

The relationships between global and local (rotated) coordinate systems are given by (14). As shown before, in the rotated ellipse system also, plastic strains are described by the associated flow rule (15).

$$
\begin{array}{cc}
\boldsymbol{\sigma}^{\prime}=Q \boldsymbol{\sigma}, & \boldsymbol{\sigma}=Q^{T} \boldsymbol{\sigma}^{\prime} \\
\dot{\boldsymbol{\varepsilon}}^{\prime}=Q \dot{\boldsymbol{\varepsilon}}, & \dot{\boldsymbol{\varepsilon}}=Q^{T} \dot{\boldsymbol{\varepsilon}}^{\prime} \\
\dot{\boldsymbol{\varepsilon}}^{\prime} p=\dot{\lambda} \frac{\partial F^{\prime}}{\partial \boldsymbol{\sigma}^{\prime}} & \dot{\boldsymbol{\varepsilon}}^{p}=Q^{T} \dot{\boldsymbol{\varepsilon}}^{p}
\end{array}
$$

where $Q$ is the rotation matrix connected with angle $\theta$.

The adaptation of the yield surface rotation in cyclic shear test is shown in Fig. 10. Similar as before, the simulations were performed for three different values of normal stress at a constant initial density and $\theta_{\max }=25^{\circ}$.

The changes in tangent stress are similar to simulations for a model that does not include rotation of the failure surface. Considering yield surface position changes by adding the angle of rotation $\theta$, results in qualitative changes in the dilation of the layer at load

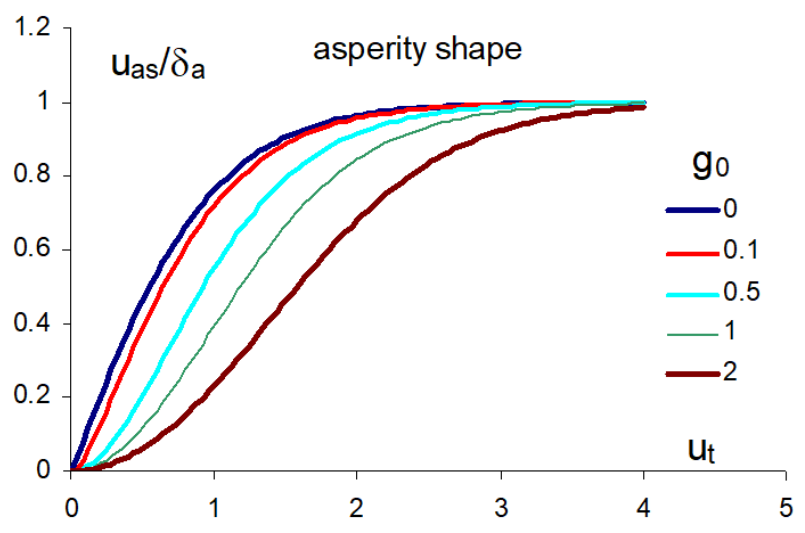

Figure 11: Shape of primary asperities depending on $g_{0}$ parameter

reversal. When the direction of shear changes, the initial compaction of the material occurs, followed by the relaxation in the further stage to the level dependent on the state of normal stress $\sigma_{n}$. In subsequent load cycles, the response is the same.

\section{Asperity interaction models}

In the model discussed here, proposed shape of the primary asperity, similar as in [31], is given by formula: 


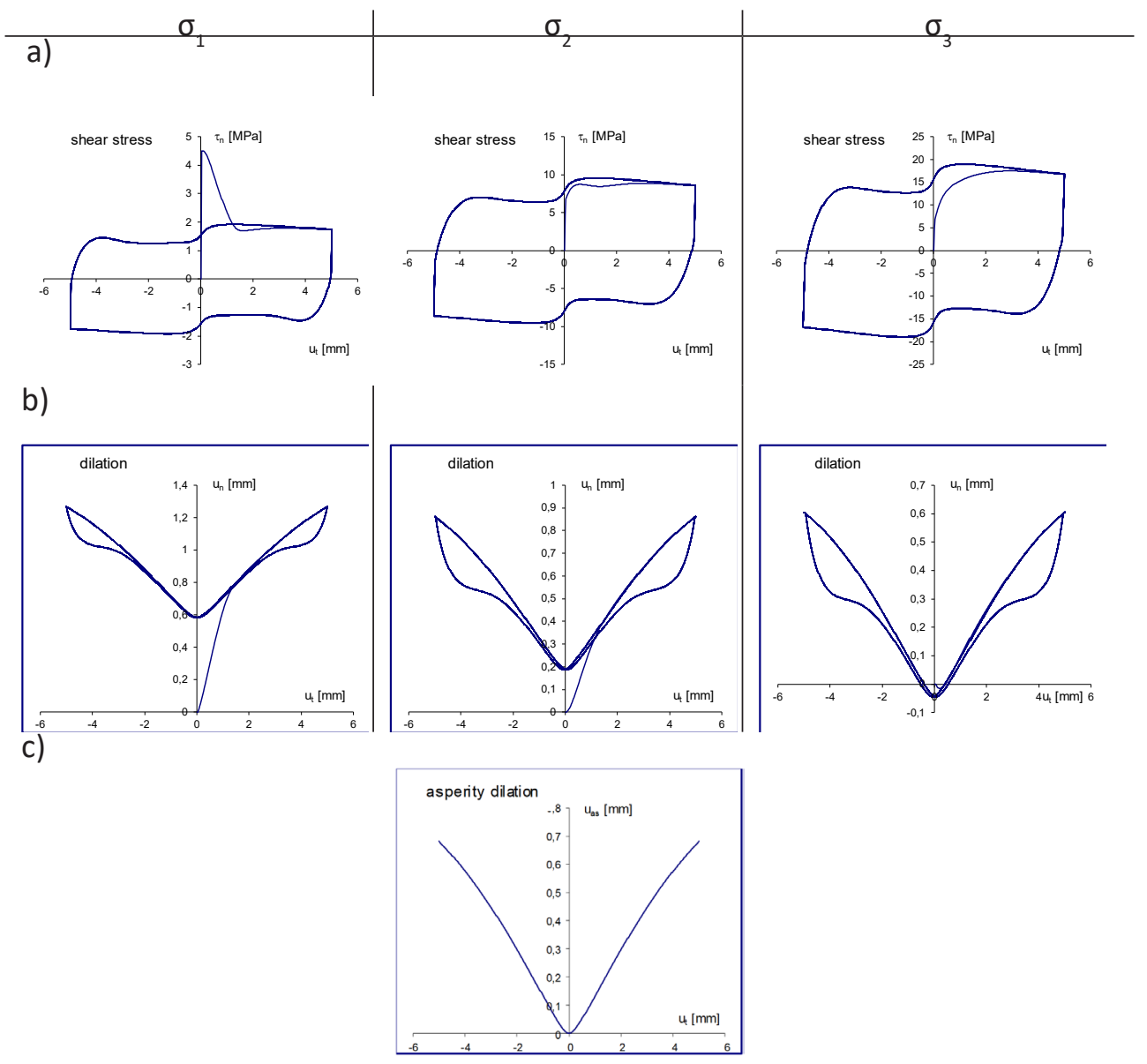

Figure 12: Simulation results for different normal loads $\left(\sigma_{1}<\sigma_{2}<\sigma_{3}, \rho_{i n i}=2.3^{\circ} 10^{3} \mathrm{~kg} / \mathrm{m}^{3}, \theta_{\max }=25^{\circ}\right.$, asperities $)$ depending on the tangential displacement $u_{t}:$ a) variations of shear stress, b) variations of dilatancy, c) asperity shape assumed for calculations

$u_{ब}=f\left(u_{t}\right)=\delta_{A} \tanh \left(\frac{\sqrt{u_{t}^{2} \tan ^{2} \psi_{0}+g_{0}^{2}}-g_{0}}{\delta_{A}}\right)$

where $\delta_{A}$ asperity height, $g_{0}$ and $\psi_{0}$ are shape parameters.

The influence of asperity shape on the parameter $g_{0}$ is shown in Fig. 11. Higher the value of the parameter $g_{0}$, the more gentle are the asperity slopes.

Simulations in Fig. 12 show the results with respect to the shape of asperity together with the elliptic yield condition and the change in $\theta$ angle value of the failure surface position. The total rotation angle $\theta_{\max }$ of the elliptic yield condition (17) is the sum of the angle $\theta$ and the angle $\psi_{a s}$ resulting from the shape of the primary asperities (18).

$$
\begin{aligned}
& \theta_{\text {max }}=\theta+\psi_{a s} \\
& \psi_{a s}=\frac{d u_{a s}\left(u_{t}\right)}{d u_{t}}
\end{aligned}
$$

The results show specific changes in the tangential stress state (Fig. 12a) and their step change when passing through the starting point for which $u_{t}=0$. The changes in the dilation of the contact layer (Fig. 12b) are the sum of changes in the asperity height and changes in the behavior of the newly created third body granular layer. In addition, Fig. 12c shows the asperity shape assumed for calculations, which is symmetrical with respect to " 0 " assuming model parameters: $\delta_{a}=2 \mathrm{~mm}, g_{0}=0.03 \mathrm{~mm}, \psi_{0}=$ $10^{\circ}$.

\section{Frictional wear and asperity degradation}

During the cyclic shearing of rocks, formation of the granulate fraction due to abrasive wear is observed. Wear occurs both by changing the shape of the asperities and by friction wear of the contact layer. 


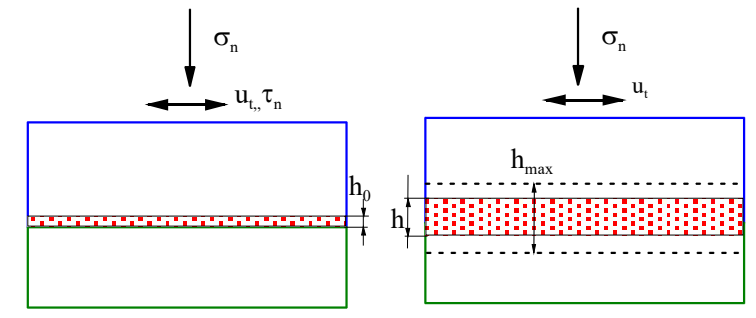

Figure 13: Third body granular layer generation due to cyclic loading

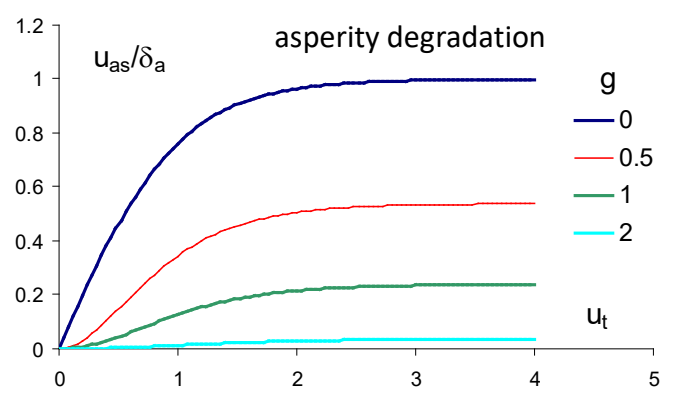

Figure 14: Evolution of asperity profile due to wear process

Figure 13 shows the generation of third body granular layer due to the shear process.

The progressive abrasive wear considerably contributes to the formation and development of this structure. Therefore, a certain form of friction wear was introduced into the model:

$$
\dot{w}=\left|\dot{u}_{t} \| \tau_{n}\right| k_{w}\left(h_{\max }-h\right)
$$

where $k_{w}$ is a wear parameter and $h_{\max }$ is maximal thickness of the granular layer.

Changes in layer height are also related to the process of wear (attrition) of primary asperities. The wear function is formulated as:

$$
g=g(\kappa)=g_{f}\left[e^{\kappa / \kappa_{0}}-1\right]
$$

where $\kappa$ is accumulated frictional work increment given by:

$$
\dot{\kappa}=\left|\tau_{n}\right|\left|\dot{u}_{t}\right|
$$

Asperity wear is described by:

$$
w_{a s}=\delta_{A} \tanh \left(\frac{\sqrt{g^{2}+g_{0}^{2}}-g_{0}}{\delta_{A}}\right)
$$

Using the above relationship, the function describing the shape of asperity with respect to their wear was modified as:

$u_{a s}=f\left(u_{t}\right)=\delta_{A}\left[\tanh \left(\frac{\sqrt{u_{t}^{2} \tan ^{2} \psi_{0}+g^{2}+g_{0}^{2}}-g_{0}}{\delta_{A}}\right)-\tanh \left(\frac{\sqrt{g^{2}+g_{0}^{2}}-g_{0}}{\delta_{A}}\right)\right]$

Figure 14 shows a gradual change in the shape of asperities as a function of the progressive wear described by (20). The higher value of wear function $g$ as the load cycles increase, the greater degradation of the asperity shape.

Figure 15 shows simulation results for the material subjected to cyclic shear described in the model with respect to assumptions presented so far (for $k_{w}=0.1^{*} 10^{-4}$ $\mathrm{mm}^{2} / \mathrm{J}, h_{i n i}=5 \mathrm{~mm}, h_{\max }=7 \mathrm{~mm}, \delta_{a}=2 \mathrm{~mm}, g_{0}=0.03 \mathrm{~mm}$, $\left.\psi_{o}=10^{\circ}, g_{f}=4 \mathrm{~mm}, \kappa_{0}=3 \mathrm{~J} / \mathrm{mm}^{2}(20)\right)$. Variations of shear stress, dilatancy and rotation angle are clearly visible. Similar to the non-wear plots (Fig. 12), sudden changes in the state of shear stress when passing through the point "0" can be observed (Fig. 15a). These step changes are smaller as the number of load cycles increases. Considering the variations of dilation (Fig. 15b), it can be seen that the contact layer height is gradually reduced. As a result of progressive wear, the plot is not symmetrical with respect to the point " 0 ", so that there is no single material response to the change of load direction.

Figure $15 \mathrm{c}$ shows the failure surface rotation angle $\theta$ changes. Also, in this case, due to wear, this parameter value changes are seen as well.

In addition, Fig. 16 shows graphs that complement the response of the material for applied normal stress $\sigma_{n}$ $=10 \mathrm{MPa}$. Figure. 16a contains the contact layer height increase from the assumed initial $(5 \mathrm{~mm})$ to the final value, that corresponds to the end of the process. Fig. 16b shows changes in the shape of asperities as the number of load cycles increases. This shape is subject to changes due to progressive wear. On the other hand, Fig. 16c shows the characteristic of changes in the behavior of the third body granular layer.

\section{Comparison with experiment}

It was decided to carry out a comparison of the proposed model with the experimental data (Fig. 17). The results of research presented by Kamonphet et al. in the paper [10] were selected as the comparative data (Fig. 17b and Fig. 18b). In the experiment, the rock sample (Tak granite) was placed in the apparatus for conducting shear tests, loaded with a normal stress $\sigma_{n}=0.5 \mathrm{MPa}$ and $\sigma_{n}=4 \mathrm{MPa}$ 


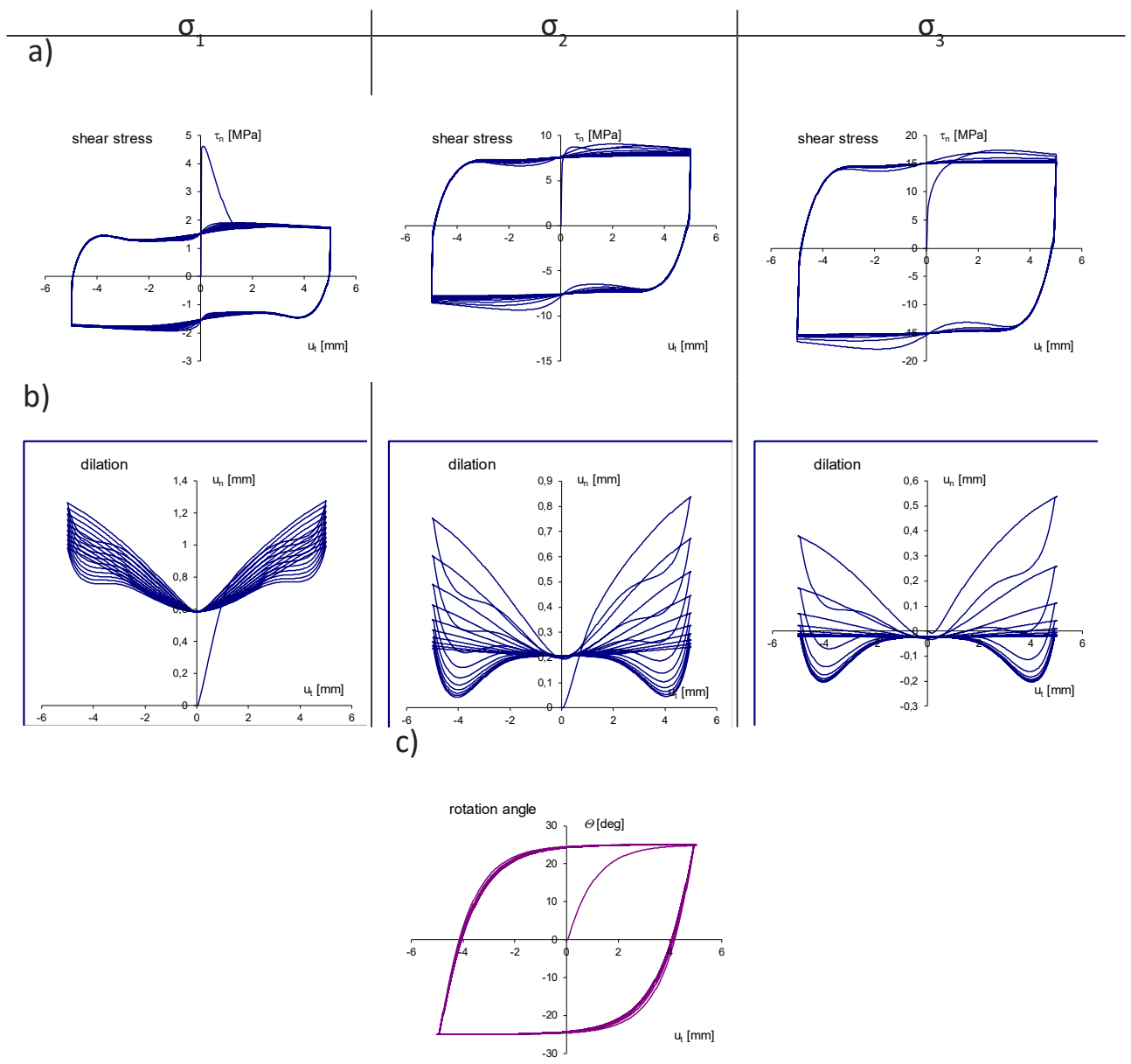

Figure 15: Simulation results for different normal loads $\left(\sigma_{1}<\sigma_{2}<\sigma_{3}, \rho_{i n i}=2.3^{\circ} 10^{3} \mathrm{~kg} / \mathrm{m}^{3}, \theta_{\max }=25^{\circ}\right.$, asperity degradation, interface layer frictional wear) depending on the tangential displacement $u_{t}:$ a) variations of shear stress, b) variations of dilatancy, $c$ ) variations of rotation angle $\theta$

a)

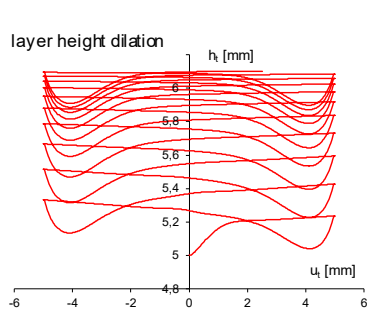

b)

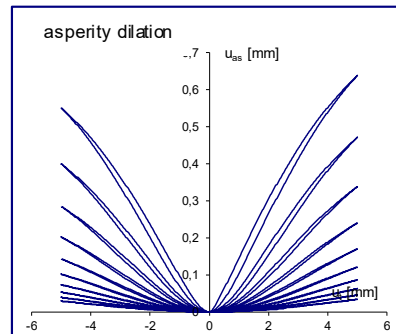

c)

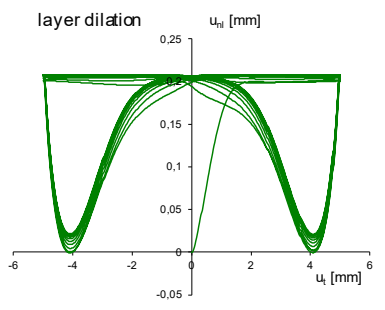

Figure 16: Supplement to simulation results given in Fig. 15 for normal load $\sigma_{n}=10 \mathrm{MPa}$ : a) variations of contact layer height, b) asperity shape degradation, $c$ ) third body layer dilation

and forced to move with the displacement amplitude $u_{0}=$ $\pm 5 \mathrm{~mm}$. Test was performed on natural joint. Simulations were carried out with the assumption of uniform, symmetrical with respect to " 0 ", shape of the asperity. The following model parameters were assumed: $h_{i n i}=0.1 \mathrm{~mm}$, $\rho_{\text {ini }}=2.1^{1} 103 \mathrm{~kg} / \mathrm{m}^{3}, \rho_{\max }=2.71^{1} 10^{3} \mathrm{~kg} / \mathrm{m}^{3}, \rho_{\text {min }}=2^{1} 10^{3} \mathrm{~kg} / \mathrm{m}^{3}$, $A_{1}=80 \mathrm{MPa}, A_{2}=0.01 \mathrm{MPa}^{-1}, C_{1}=1.1 \mathrm{MPa}, C_{2}=3, k_{t}=1, k_{w}=$
$0 \mathrm{~mm}^{2} / \mathrm{J}, h_{\max }=10 \mathrm{~mm}, \delta_{a}=0.1 \mathrm{~mm}, g_{0}=0.0 \mathrm{~mm}, \psi_{0}=12.5^{\circ}$, $g_{f}=1 \mathrm{~mm}, \theta_{\max }=15^{\circ}, \kappa_{0}=0.25 \mathrm{~J} / \mathrm{mm}^{2}$. These parameters were chosen so as to best fit the real changes.

When comparing the characteristics with each other, good qualitative agreement obtained by simulation and experiment can be noticed. 
a)
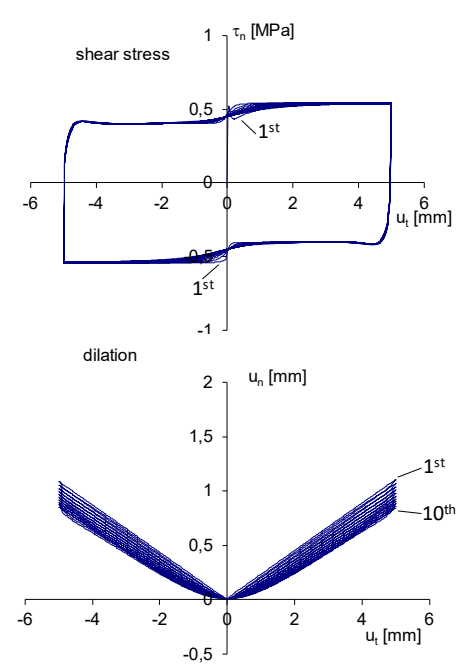

b)
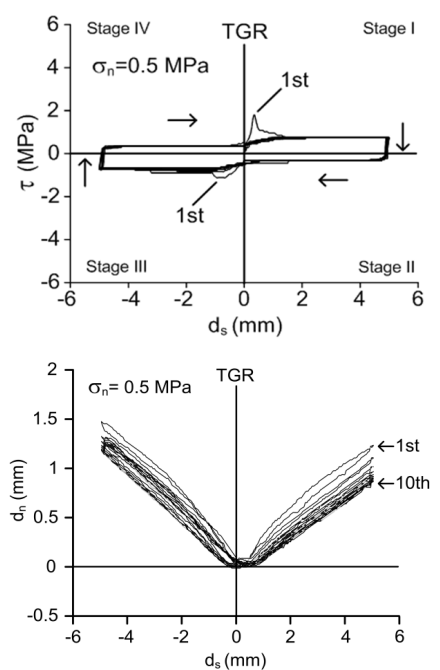

Figure 17: Simulation vs. experiment: a) simulation results, b) results obtained in experiment for normal load $\sigma_{n}=0.5 \mathrm{MPa}$

a)
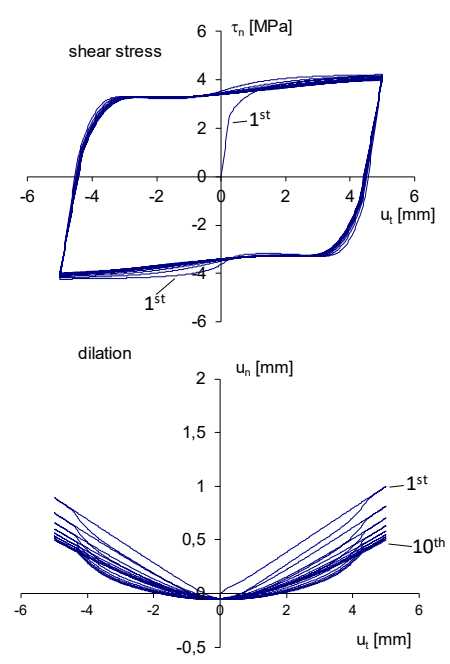

b)
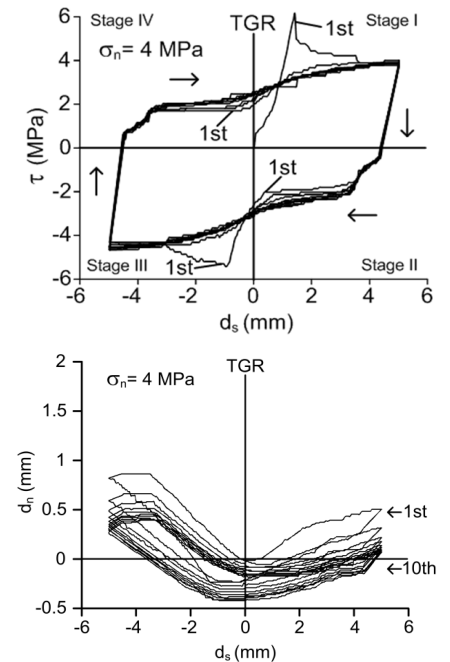

Figure 18: Simulation versus experiment: a) simulation results, b) results obtained in experiment for normal load $\sigma_{n}=4 \mathrm{MPa}$

In case of tangential stress, a step change when passing through the point " 0 " in the first load cycle can be seen. When the number of cycles increases, these steps are gradually flattened and the changes in contact layer height are getting smaller. The adoption of assumptions regarding the abrasive wear of both the asperities and the creation of the third body granular layer were the most appropriate. This can be observed comparing the asymmetrical (relative to "0") dilation diagrams obtained in the simulation and the experiment.

Differences in the quantitative agreement occurred, especially in the first shear stage. This is due to the assumption of uniform, symmetrical with respect to " 0 ", shape of the asperity. As can be seen in the above figures, the model is able to describe the nature of changes in both tangential stress and dilation with wear, but not the first peak, which may result from fitting together two parts of the tested rock or from sudden destruction in the first stage of surface asperities. Apart from the first peak, the rest of the shear process is modeled correctly.

For cyclic shearing under high normal pressure, the dilation decreases with increasing number of cycles. This effect is due to wear and degradation of asperities and formation of granular fraction on the contact surfaces. In the cyclic test, the effect of the compaction when changing the shear direction is observed. 
A large number of laboratory tests are available regarding the influence of the shape of the surface asperities' profile on the cyclic shear process, whereas insufficiency is based on numerical modeling. Most of the studies on the shear behavior of rock joints are concerning the pre-peak and peak shear strength in monotonic loading. Presented model provides the ability to study the post-peak behavior of rock joints in cyclic test. However, further studies are required to investigate the correct mapping of real changes, especially in the first shear stage. This will be achieved by applying the damage function.

\section{Conclusion}

This paper analyzes the deformation of brittle materials on contact surfaces subjected to cyclic loads. It was shown, that some of the effects observed in experiments may result from more than one mechanism. Simple conditions were proposed providing description of these mechanisms.

A comprehensive model containing:

- elliptic yield condition with density hardening/ softening with associated flow rule,

- rotating failure surfaces simulating roughness and configurational rearrangement of grains and particles at interface layer,

- interaction of primary asperities,

- asperity wear,

- frictional wear

allows for good qualitative agreement of the material response subjected to cyclic shear in relation to the actual experiment. It was shown that those assumptions can be used for the description of wide range of brittle interfaces response.

This analytical model should be treated as a preliminary, covering the effects of degradation of surface asperities.

\section{References}

[1] Bahaaddini M., Hagan P.C., Mitra R., Khosravi M.H.: Experimental and numerical study of asperity degradation in the direct shear test, Engineering Geology 204 (2016), 41-52

[2] Bahaaddini M., Sharrock G., Hebblewhite B.K.: Numerical direct shear tests to model the shear behaviour of rock joints, Computers and Geotechnics 51 (2013), 101-115
[3] Dafalias Y.F., Popov E.P.: A model of nonlinearly hardening materials for complex loading, Acta Mechanica (1975), 21:173192

[4] Fathi A., Moradian Z., Rivard P., Ballicy G., Boyd A.J.: Geometric Effect of Asperities on Shear Mechanism of Rock Joints, Rock Mech Rock Eng (2016) 49:801-820, DOI 10.1007/s00603-0150799-6

[5] Hashiguchi K.: Constitutive equations of elastoplastic materials with anisotropic hardening and elastic-plastic transition, J.

Appl. Mech., ASME (1981) 48:297-301

[6] Hoek E. (ed.): Practical Rock Engineering, 2007

[7] Huang M., Chen Y., Gu X.: Discrete element modeling of soilstructure interface behavior under cyclic loading, Computers and Geotechnics 107 (2019), 14-24

[8] Indraratna B., Thirukumaran S., Brown E.T., Zhu SP.: Modelling the Shear Behaviour of Rock Joints with Asperity Damage Under Constant Normal Stiffness, Rock Mech. Rock Eng. (2015) 48:179-195, DOI 10.1007/s00603-014-0556-2

[9] Jarzębowski A., Mróz Z.: On slip and memory rules in elastic, friction contact problems, Acta Mechanica, 102, 199-216 (1994)

[10] Kamonphet T., Khamrat S., Fuenkajorn K.: Effects of cyclic shear loads on strength, stiffness and dilation of rock fractures, Songklanakarin J. Sci. Technol. (2015), 37 (6), 683-690

[11] Kou M., Liu X., Tang S., Wang Y.: Experimental study of the prepeak cyclic shear mechanical behaviors of artificial rock joints with multiscale asperities, Soil Dynamics and Earthquake Engineering, 120 (2019) 58-74

[12] Lee H.S., Park Y.J., Cho T.F., You K.H.: Influence of asperity degradation on the mechanical behavior of rough rock joints under cyclic shear loading, International Journal of Rock Mechanics \& Mining Sciences, 38 (2001), 967-980

[13] Li, Y. Oh, J., Mitra, R., Hebblewhite, B.: A joint asperity degradation model based on the wear process, 49th US Rock Mechanics/Geomechanics Symposium, San Francisco, CA, USA, 28 June- 1 July 2015.

[14] Liu Q., Tian Y., Liu D., Jiang Y.: Updates to JRC-JCS model for estimating the peak shear strength of rock joints based on quantified surface description, Engineering Geology 228 (2017), 282-300

[15] Liu X.G., Zhu W.C., Yu Q.L., Chen S.J., Li R.F.: Estimation of the joint roughness coefficient of rock joints by consideration of two-order asperity and its application in double-joint shear tests, Engineering Geology 220 (2017) 243-255

[16] Liu X.R., Kou M.M., Lu Y.M., Liu Y.Q.: An experimental investigation on the shear mechanism of fatigue damage in rock joints under pre-peak cyclic loading condition, International Journal of Fatigue 106 (2018) 175-184

[17] Ma S., Chuan H., Zhao Z., Nie W., Zhu X., Zhang Z.: Modeling of Rock Joints Under Cyclic Loading Conditions Using Discontinuous Deformation Analysis, Rock Mech Rock Eng (2017), 50:1205-1215, DOI 10.1007/s00603-016-1158-y

[18] Ma S., He C., Zhao Z., Nie W. Zhu X., Zhang Z.: Modeling of Rock Joints Under Cyclic Loading Conditions Using Discontinuous Deformation Analysis, Rock Mech Rock Eng. (2017), 50:12051215, DOI 10.1007/s00603-016-1158-y

[19] Maciejewski and Mróz Z.: Deformation response of geomaterial interfaces coupled with progressive damage and wear, 37th Solid Mechanics Conference SolMech 2010, Book of Abstracts, 2010. 
[20] Maciejewski J., Jarzębowski A.: Application of kinematically admissible solutions to passive earth pressure problems, International Journal of Geomechanics, 2004, vol. 4 (2), 127-136

[21] Maciejewski J.: Analiza stanów pokrytycznych w procesach urabiania gruntów, rozprawa doktorska, IPPT PAN, Warszawa 1996

[22] Mirzaghorbanali A., Nemcik J., Aziz N.: Effects of Cyclic Loading on the Shear Behaviour of Infilled Rock Joints Under Constant Normal Stiffness Conditions, Rock Mech Rock Eng. (2014) 47:1373-1391

[23] Mróz Z., Maciejewski J.: Post-critical response of soils and shear band evolution, Proc. $3^{\text {rd }}$ Int. Workshop On localization and Bifurcation Theory for Soils and Rocks, Grenoble (Aussois), France, 19-32, 1994

[24] Mróz Z., Norris V.A., Zienkiewicz O.C.: An anisotropic hardening model for soils and its application to cyclic loading, Int. J. for Numerical and Analytical Meth. in Geomech. (1978) 2:203-221

[25] Mróz Z., Pietruszczak S.: A constitutive model for sand with anisotropic hardening rule, Int. J. for Numerical and Analytical Meth. in Geomech. (1983) 7:305-320

[26] Niktabar S.M.M., Rao S.K., Shrivastava A.K.: Effect of rock joint roughness on its cyclic shear behavior, Journal of Rock Mechanics and Geotechnical Engineering, 9 (2017), 1071-1084

[27] Nova R.: A constitutive model for soils under monotonic and cyclic loadings, Soil Mechanics-Transient Cyclic Loads, Eds. Pande G.N. and Zienkiewicz O.C., John Wiley \& Sons Inc., 343-373

[28] Oda M.: A mechanical and statistical model of granular material, Soils and Foundations (1974), 14, 1:13-27

[29] Park JW., Song J.: Numerical simulation of a direct shear test on a rock joint using a bonded-particle model, International Journal of Rock Mechanics \& Mining Sciences 46 (2009), 1315-1328

[30] Roscoe K.H., Burland J.B.: On the generalized stress-strain behavior of 'wet' clay, Engineering Plasticity, Eds. Heyman and Leckie F.A., Cambridge Univ. Press, Cambridge, 535-608

[31] Stupkiewicz S., Mróz Z.: Modelling of friction and dilatancy effects at brittle interfaces for monotonic and cyclic loading, Journ. Theoret. Appl. Mech., 39 (2001), 707-739

[32] Tang Z., Liu Q., Xia C., Song Y., Huang J., Wang C.: Mechanical model for predicting closure behavior of rock joints under normal stress. Rock Mech Rock Eng (2014), 47:2287-2298

[33] Xia C, Tang Z, Xiao W, Song Y.: New peak shear strength criterion of rock joints based on quantified surface, Rock Mech. Rock Eng. (2014) 47 :387-400, doi:10.1007/s00603-0130395-6

[34] Zhang Q., Wu C., Fei X., Jang B.A., Liu D.: Time-dependent behavior of rock joints considering asperity degradation, Journal of Structural Geology 121 (2019), 1-9

[35] Zheng B., Qi S.: A new index to describe joint roughness coefficient (JRC) under cyclic shear, Engineering Geology, 212 (2016), 72-85 